\title{
Editorial
}

\section{Record citations in 2007, but impact factor slips}

Through publishing, authors disseminate their work in order that others may see it and act upon it in some way. This is one of the principal ways that the scientific community interacts and exchanges information. It has become increasingly important that the influence of an author's body of work, or of an individual publication, or of an entire journal somehow be assessed. The importance of such an assessment is viewed differently in different countries, institutions and disciplines and by different individuals. For a number of years the Institute for Scientific Information (ISI) has released annual statistics on citations of articles published in previous years in scientific journals. A number of different summary statistics are produced, the most widely discussed being the impact factor. I have used previous editorials to keep readers informed of the most recent statistics for the British Journal of Nutrition $(B J N)$ and to analyse them in relation to those of comparator journals and to temporal changes ${ }^{(1-3)}$. The statistics for 2007 were published by the ISI in July 2008.

The $B J N$ is listed in the Nutrition and Dietetics category of ISI Journal Citation Reports ${ }^{\circledR}$. In 2007 there were fifty-six journals listed in this category, including review journals and journals in the areas of obesity (for example, Obesity Research, International Journal of Obesity) and lipidology (for example, Progress in Lipid Research, Lipids). The impact factor of a journal is calculated as the number of citations of papers published in the previous 2 years divided by the number of papers published in those two years. Thus, the impact factor for 2007 (issued in 2008) is based upon the number of citations during 2007 of papers published in a particular journal in 2005 and 2006 divided by the number of papers published in that journal in 2005 and 2006. Clearly this favours very rapidly moving areas of research. Hence journals such as Nature, Science and Cell have high impact factors $(28.75,26.37$ and 29.88, respectively, for 2007). For the past 6 years the two highest ranked journals in the Nutrition and Dietetics category have been Progress in Lipid Research and Annual Reviews in Nutrition, with impact factors of 11.19 and 8.69, respectively, for 2007. Table 1 lists the impact factors for the $B J N$ and nine comparator journals over the period 2001 to 2007 inclusive. The comparator journals all publish a similar range of material as does the $B J N$, including molecular, cellular, whole body, human, clinical, public health and experimental animal nutrition and, in most cases, also farm animal nutrition. It is evident that the American Journal of Clinical Nutrition is firmly established as the highest ranked journal in this category that is not solely limited to publishing review articles. Unfortunately, in 2007 , the impact factor of the $B J N$ slipped from 2.71 to 2.34 (1441 citations in 2007 to the 616 articles published in
2005 and 2006) and it fell below its historic ranking within the top ten nutrition and dietetics journals. I have calculated that if each paper published in the $B J N$ in 2005 and 2006 was cited just once more than it actually was, the impact factor would have been 3.34! Readers may be interested in the impact factors of our sister journals. For 2007 these were 3.93, 1.89 and 1.86 for Proceedings of the Nutrition Society (ranked 6/56), Nutrition Research Reviews (26/56) and Public Health Nutrition (27/56), respectively.

Table $2^{(4-12)}$ lists the articles published in the $B J N$ during 2005 and 2006 that were most cited in 2007. This Table indicates the importance of review articles and the Horizons in Nutritional Science series to the impact factor of the journal. Although the articles published in 2005 continue to be cited (Table 2), they will not contribute to the impact factor for 2008 which will be based upon articles published in 2006 and 2007. This Table hints at the reason for the slip in impact factor for 2007. The top nine cited papers from 2005 and 2006 were cited between 11 and 21 times (average 14). In contrast, the top nine papers from 2004 and 2005 were cited between 13 and 79 times in 2006 (average 25) ${ }^{(3)}$.

One argument against the importance of impact factor in indicating the 'value' of a journal is that the time frame over which it is calculated is too short to really reflect the impact that the articles that a journal publishes will have. Thus, alternative measures of article citations are available. These include the total number of citations made to articles published in a journal, and the cited half-life of articles. Table 3 lists the total number of citations made to articles published in the $B J N$, irrespective of their year of publication, during the years 2000 to 2007. In 2007 articles published in the $B J N$ were cited 9843 times, placing the BJN fifth in the Nutrition and Dietetics category for total citations in 2007. It is apparent that the total number of citations of articles in the journal has increased year-on-year and has increased by almost $85 \%$ since 2000 . The cited half-life of a journal (Table 3 ) is the median age of the articles published in that journal that are cited in the reporting year. Thus, publication of articles that remain important (or controversial) long after they are published will result in a long cited half-life. For 2007 Nature, Cell and Science have cited half-lives of 8.0, 8.7 and 8.0 years, respectively. Thus, these journals are publishing articles that are seen as important in the short term, as judged by the high impact factor, but which remain important for many years after publication, as judged by the cited half-life. There may, of course, be other influences on cited half-life. For example, publication of articles of little interest by a journal that in the past has published articles that still remain of interest will result in a long cited half-life. 
Table 1. Impact factor of the British Journal of Nutrition and comparator journals over the period 2001-7*

\begin{tabular}{|c|c|c|c|c|c|c|c|}
\hline & \multicolumn{7}{|c|}{ Impact factor and rankingt } \\
\hline & 2001 & 2002 & 2003 & 2004 & 2005 & 2006 & 2007 \\
\hline American Journal of Clinical Nutrition & $5.02(2 / 50)$ & $5.60(3 / 50)$ & $5.69(3 / 53)$ & $5.43(3 / 53)$ & $5.85(3 / 53)$ & $6 \cdot 56(3 / 55)$ & $6 \cdot 60(3 / 56)$ \\
\hline Journal of Nutrition & $3.25(5 / 50)$ & $3.62(4 / 50)$ & $3.32(5 / 53)$ & $3 \cdot 25(7 / 53)$ & $3.69(7 / 53)$ & $4.01(5 / 55)$ & $3.77(7 / 56)$ \\
\hline Clinical Nutrition & $2.46(9 / 50)$ & $1.55(22 / 50)$ & $1.19(32 / 53)$ & $2.02(18 / 53)$ & $2 \cdot 29(15 / 53)$ & $2.47(15 / 55)$ & $2 \cdot 88(14 / 56)$ \\
\hline British Journal of Nutrition & $1.99(16 / 50)$ & $2.49(7 / 50)$ & $2.62(9 / 53)$ & $2 \cdot 71(10 / 53)$ & $2.97(9 / 53)$ & $2.71(12 / 55)$ & $2 \cdot 34(17 / 56)$ \\
\hline European Journal of Clinical Nutrition & $1.77(20 / 50)$ & $1.94(18 / 50)$ & $1.86(19 / 53)$ & $2 \cdot 13(16 / 53)$ & $2 \cdot 16(18 / 53)$ & $2.12(22 / 55)$ & $2 \cdot 33(18 / 56)$ \\
\hline $\begin{array}{l}\text { Journal of the American College of } \\
\text { Nutrition }\end{array}$ & $1.53(22 / 50)$ & $2 \cdot 17(11 / 50)$ & $2.98(7 / 53)$ & $2 \cdot 80(9 / 53)$ & $2 \cdot 21(17 / 53)$ & $2.45(16 / 55)$ & $2 \cdot 28(19 / 56)$ \\
\hline Nutrition & $1.43(23 / 50)$ & $2 \cdot 27(10 / 50)$ & $2 \cdot 32(11 / 53)$ & $1.96(19 / 53)$ & $2.06(20 / 53)$ & $2 \cdot 23(20 / 55)$ & $2 \cdot 10(21 / 56)$ \\
\hline European Journal of Nutrition & $2 \cdot 13(13 / 50)$ & $1.64(21 / 50)$ & $1.68(22 / 53)$ & $2.09(17 / 53)$ & $2 \cdot 26(16 / 53)$ & $2.36(18 / 55)$ & $2.09(23 / 56)$ \\
\hline Annals of Nutrition and Metabolism & $1.01(31 / 51)$ & $1.08(28 / 50)$ & $1.81(20 / 53)$ & $1.07(35 / 53)$ & $1.56(29 / 53)$ & $1.62(30 / 55)$ & $1.83(28 / 56)$ \\
\hline Nutrition Research & $0.60(37 / 50)$ & $0.79(35 / 50)$ & $0.72(39 / 53)$ & $0.57(41 / 53)$ & $0.77(40 / 53)$ & $0.73(44 / 55)$ & $0.68(51 / 56)$ \\
\hline
\end{tabular}

* Data are from Institute for Scientific Information Journal Citation Reports ${ }^{\circledR}$

†Ranking amongst journals in the Nutrition and Dietetics subject category is shown in parentheses beside each impact factor (for example, British Journal of Nutrition ranked seventh out of fifty journals in 2002).

Table 2. Articles published in the British Journal of Nutrition in 2005 and 2006 that were most highly cited in $2007^{*}$

\begin{tabular}{llcr}
\hline & Type of article & Citations in 2007 & Total citations to date \\
\hline Kaput et al. $(2005)^{(4)}$ & Horizons & 21 & 35 \\
Roberfroid $(2005)^{(5)}$ & Supplement & 19 & 37 \\
Zittermann et al. $(2005)^{(6)}$ & Review & 15 & 30 \\
Milder et al. $(2005)^{(7)}$ & Full paper & 14 & 49 \\
Albers et al. $(2005)^{(8)}$ & Workshop report & 12 & 22 \\
Fuchs et al. $(2005)^{(9)}$ & Horizons & 12 & 21 \\
Brighenti et al. $(2005)^{(10)}$ & Full paper & 11 & 23 \\
Forchielli \& Walker $(2005)^{(11)}$ & Supplement & 11 & 23 \\
Guarner et al. $(2005)^{(12)}$ & Review & 11 & 20 \\
\hline
\end{tabular}

* Data were obtained from Institute for Scientific Information Web of Science ${ }^{\circledR}$ on 14 August 2008.

Table 3. Citation statistics for the British Journal of Nutrition 2000-7

\begin{tabular}{|c|c|c|c|c|c|c|c|c|}
\hline & 2000 & 2001 & 2002 & 2003 & 2004 & 2005 & 2006 & 2007 \\
\hline Impact factor & $2 \cdot 415$ & 1.989 & 2.491 & $2 \cdot 616$ & $2 \cdot 710$ & 2.967 & 2.708 & 2.339 \\
\hline Total citations & 5515 & 5360 & 6205 & 7144 & 7204 & 7893 & 8665 & 9843 \\
\hline Immediacy index & 0.307 & 0.283 & 0.402 & 0.500 & 0.515 & 0.289 & 0.300 & 0.337 \\
\hline
\end{tabular}

The cited half-life of the $B J N$ for 2007 was $7 \cdot 1$ years, indicating that half of the citations to articles to $B J N$ in 2007 were to articles published in 2000 or before. Thus, it seems to me that the $B J N$ is publishing articles that are seen as important in the short term, as judged by the reasonably high impact factor (within the journal category), but which remain important for many years, as judged by the cited half-life. For comparison, the cited half-lives for the American Journal of Clinical Nutrition and the Journal of Nutrition for 2007 were 7.7 and 6.5 years, respectively.

The final statistic that is shown in Table 3 is the immediacy index. This is calculated as citations of articles published in the reporting year (for example, 2007) divided by papers published in that same year. It is a measure of how immediately important (or controversial) published papers are. For 2007, the immediacy index of the $B J N$ was $0 \cdot 337$. For comparison, the immediacy indexes for the American Journal of Clinical
Nutrition and the Journal of Nutrition for 2007 were 1.058 and $0 \cdot 704$, respectively.

As I indicated in my previous editorials ${ }^{(2,3)}$, the $B J N$ is receiving more submissions and is publishing more articles than ever before. This suggests that the journal is in very good health and is viewed favourably by researchers within the discipline. The communications that $\mathrm{I}$ receive indicate that authors want to publish their work in the $B J N$. My aim is to act to improve the impact factor in order that the prestige and attractiveness of the $B J N$ are maintained, in the face of mounting competition from other journals, and that its perceived quality is enhanced. This will require a more stringent set of criteria for acceptance of papers and will undoubtedly be unpopular with some authors. However, an improvement in (perceived) quality of the $B J N$ will assure its place amongst the top journals in the field and as Editor-in-Chief it is my role to strive for this. 
Philip C. Calder

Editor-in-Chief Institute of Human Nutrition School of Medicine University of Southampton Southampton

$U K$

email pcc@soton.ac.uk doi:10.1017/S0007114508066816

\section{References}

1. Calder PC (2006) Carpe diem. Br J Nutr 95, 1-4.

2. Calder PC (2007) Floruit floreat. Br J Nutr 97, 1-3.

3. Calder PC (2007) Happy Birthday BJN! Br J Nutr 98, 447-450.

4. Kaput J, Ordovas JM, Ferguson L, et al. (2005) The case for strategic international alliances to harness nutritional genomics for public and personal health. Br J Nutr 94, 623-632.

5. Roberfroid MB (2005) Introducing inulin-type fructans. $\mathrm{Br} J$ Nutr 93, Suppl. 1, S13-S25.
6. Zittermann A, Schleithoff SS \& Koerfer R (2005) Putting cardiovascular disease and vitamin D insufficiency into perspective. Br J Nutr 94, 483-492.

7. Milder IE, Arts IC, van de Putte B, Venema DP \& Hollman PC (2005) Lignan contents of Dutch plant foods: a database including lariciresinol, pinoresinol, secoisolariciresinol and matairesinol. Br J Nutr 93, 393-402.

8. Albers R, Antoine JM, Bourdet-Sicard R, et al. (2005) Markers to measure immunomodulation in human nutrition intervention studies. Br J Nutr 94, 452-481.

9. Fuchs D, Winkelmann I, Johnson IT, Mariman E, Wenzel U \& Daniel H (2005) Proteomics in nutrition research: principles, technologies and applications. Br J Nutr 94, 302-314.

10. Brighenti F, Valtueña S, Pellegrini N, Ardigò D, Del Rio D, Salvatore S, Piatti P, Serafini M \& Zavaroni I (2005) Total antioxidant capacity of the diet is inversely and independently related to plasma concentration of high-sensitivity C-reactive protein in adult Italian subjects. Br J Nutr 93, 619-625.

11. Forchielli ML \& Walker WA (2005) The role of gut-associated lymphoid tissues and mucosal defence. Br J Nutr 93, Suppl. 1, S41-S48.

12. Guarner F, Perdigon G, Corthier G, Salminen S, Koletzko B \& Morelli L (2005) Should yoghurt cultures be considered probiotic? Br J Nutr 93, 783-786. 